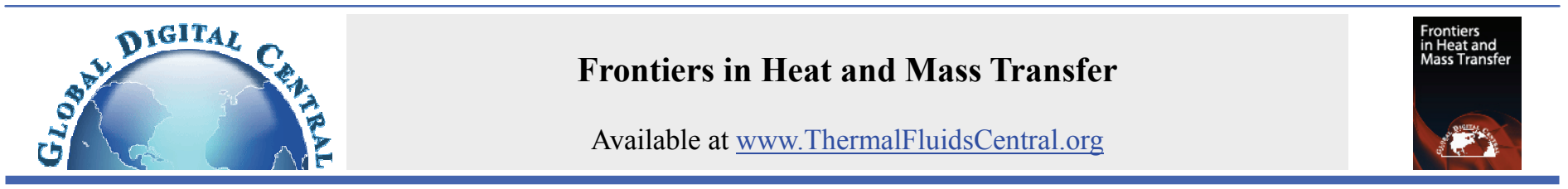

\title{
PREDICTION OF BINARY MIXTURE BOILING HEAT TRANSFER IN SYSTEMS WITH STRONG MARANGONI EFFECTS
}

\author{
Kenneth M. Armijo and Van P. Carey ${ }^{*}$ \\ Mechanical Engineering Department, University of California, Berkeley, CA 94720, USA
}

\begin{abstract}
This paper investigates the impact of Marangoni phenomena for low concentrations of 2-propanol/water and methanol/water mixtures. In real systems the addition of small levels of surface-active contaminants can affect the surface tension of the liquid-vapor interface and thermodynamic conditions in this region. Analysis was performed for three widely accepted binary mixture correlations to predict heat flux and superheat values for subatmospheric experimental data using bulk fluid and film thermodynamic properties. Due to the non-ideal nature of these alcohol/water mixtures, this study also employs an average pseudo single-component (PSC) coefficient in place of an ideal heat transfer coefficient (HTC) to improve the correlation predictions. This investigation evaluates the ability for these correlations to predict strong Marangoni effects of mixtures that have large surface tension variation with concentration under subatmospheric conditions. It is not always clear that evaluation of bulk fluid properties will satisfactorily account for Marangoni effects. Analysis is also performed to assess correlation predictions for interfacial film properties rather than that of the bulk fluid. The results indicate that the use of film properties along with the PSC coefficient improves heat flux model predictions of subatmospheric experimental data by as much as $59.3 \%$ for $0.015 \mathrm{M}$ 2-propanol and $49.1 \%$ for $0.04 \mathrm{M}$ methanol/water mixtures, where strong Marangoni effects are believed to be more evident.
\end{abstract}

Keywords: Binary Mixtures, Marangoni Effects, Interfacial Properties

\section{INTRODUCTION}

Binary mixtures of alcohol and water play an important role in the performance of heat transfer equipment. A heat pipe study by Armijo and Carey (2010) demonstrated the use of low concentrations of 2propanol/water mixtures, when compared to pure water, can increase the critical heat flux (CHF) by as much as $52 \%$, while lowering the evaporator wall superheat. The Marangoni effect was further explored by McGillis and Carey (1993) who investigated the boiling performance of several alcohol/water binary mixtures and compared them to their respective pure components. Their study found that small additions of a volatile alcohol were able to increase the CHF condition above that for pure water, while higher concentrations decreased the $\mathrm{CHF}$ to that of the pure alcohol. Results showed that small additions of 2-propanol reduced fluctuations in the evaporator wall temperature from that of pure water, possibly due to a reduction in the bubble departure size. It was found that although the average superheat did not vary significantly with concentration, the CHF did, reaching a maximum at approximately $0.05 \mathrm{M}$ 2-Propanol. They concluded that correlations based on effective subcooling (1993) were not able to accurately predict the CHF condition for all alcohol/water mixtures and the influence of the Marangoni effect was the principle cause for the $\mathrm{CHF}$ variation of boiling liquid mixtures.

Carey (2008) explained that the stability mechanism and cellular flow in real systems resulting from the Marangoni effect can be significantly altered by the presence of small amounts of surface-active contaminants that tend to flow from regions of high to low temperature. Concurrently, the Marangoni effect also causes vapor bubbles in a liquid medium with an imposed temperature gradient to move toward the high temperature region as the liquid flow that causes this motion is driven by interfacial tension gradients.

A number of investigators (eg., Stephan and Körner, 1969, Fujita et al., 1997, Kandlikar, 1998, Jungnickel et. al., 1982, Calus and Leonidopoulus, 1974) have developed correlations for binary mixtures containing a solute and a volatile solvent. Table 1 presents three correlations selected for comparison study with subatmospheric experimental data by McGillis (1996) for binary mixtures of 2propanol/water and methanol/water.

The pioneering work of Stephan and Körner (1969) developed a heat transfer coefficient correlation based on the absolute value of the difference between a mixture's more volatile component vapor and liquid molar concentrations. These authors considered the relationship between the temperature difference driving force required to obtain the same heat flux with a binary mixture and with each of its two pure components. They provided experimental evidence that the wall superheat for a mixture varies linearly with the concentration if the liquid-vapor equilibrium relationship approaches ideality when the mass transfer driving force is very small. $A_{0}$ is an empirical binary constant determined empirically at atmospheric pressure. The authors stated that $A_{0}$ can be regarded as a constant for the range of mixture concentrations exhibiting ideal liquid-vapor equilibrium behavior. This correlation considered bulk thermodynamic properties and assumed complete miscibility between pure liquids.

Fujita et al. (1997) developed an empirical correlation based on a previous model by Fujita and Tsutsui (1996) by replacing the heat flux term with one that included an ideal wall superheat, $\Delta T_{i d}$. They compared their correlation with literature data sets and their own

*Corresponding author. Email: vcarey@me.berkeley.edu 
experimental mixture results of several alcohol/water mixtures at atmospheric pressure. Although their correlation predicted alcohol/water mixture data to within less than $20 \%$, larger deviations were observed with refrigerant mixture data from Jungnickel et al. (1982) for R-22/R-12 and R23/R-12 systems. Component 1 within the forcing term in Eqn. 2 corresponds to the more volatile component with a lower boiling point than the solute component 2 .

Rather than using an ideal weighted-average coefficient, a predictive model was developed by Kandlikar (1998), which is based on an average PSC coefficient which accounts for property effects in binary mixtures.

$$
\begin{aligned}
h_{p s c}=h_{\text {avg }}\left(\frac{T_{\text {sat }, m}}{T_{\text {sat }, \text { avg }}}\right)^{-0.674}\left(\frac{\Delta h_{l v, m}}{\Delta h_{l v, a v g}}\right)^{0.371}\left(\frac{\rho_{v, m}}{\rho_{v, a v g}}\right)^{0.297} \\
\times\left(\frac{\sigma_{m}}{\sigma_{\text {avg }}}\right)^{-0.317}\left(\frac{k_{l, m}}{k_{l, a v g}}\right)^{0.284}
\end{aligned}
$$

To account for real mixture properties, the average heat transfer coefficient is corrected with the form,

$$
h_{\text {avg }}=0.5\left[x_{1} h_{l, 1}+\left(1-x_{1}\right) h_{l, 2}+\left(\frac{x_{1}}{h_{l, 1}}+\frac{\left(1-x_{1}\right)}{h_{l, 2}}\right)^{-1}\right]
$$

Kandlikar's theoretical model, as outlined by Carey (2008), was developed to calculate equilibrium concentrations at the interface of the bubble as it approaches the asymptotic growth condition. In his work, Kandlikar presented comparisons of his correlation with those of Fujita et al (1998) and Calus and Leonidopolous (1974) for experimental data of various binary mixtures. His binary mixture heat transfer coefficient correlation was derived solely on a theoretical basis by applying a onedimensional model for heat and mass transfer at the bubble liquid-vapor interface under diffusion-controlled growth conditions. Kandlikar also suggested that the correction factor for mass diffusion effects, $F_{D}$ varies for different volatility parameter ranges.

The three correlations used here were originally investigated for pool boiling of binary mixtures under atmospheric conditions with thermodynamic properties evaluated based on that of the bulk fluid. However during nucleate pool boiling, as the system pressure or temperature are reduced below atmospheric conditions, boiling and dew point temperatures decrease, affecting other system thermodynamic properties. Additionally, most nucleate pool boiling binary mixture correlations have traditionally evaluated thermodynamic properties based on bulk fluid conditions. However, as shown by Kandlikar (1998) the volatile component mole fraction can vary at the liquid-vapor interface of a bubble from that of the bulk fluid.

In most heat pipes, boiling of the working fluid occurs under low pressure conditions. This investigation first analyzes model predictions of all three correlations with bulk fluid properties for subatmospheric pressure data, for both weak $(0.1 \mathrm{M})$ and strong $(<0.1 \mathrm{M})$ Marangoni effect concentrations where large surface tension variation are evident. It is not always clear that evaluation of the bulk mixture properties will allow the correlations to effectively predict mixture fluids where strong Marangoni effects are present. Therefore for these same concentrations, this study then investigates correlation predictions using boundary layer film properties to improve accuracy between the models and experimental data. These are determined by an average of the properties at the liquid-vapor interface and those of the bulk fluid. An idealization is made that the temperature at the liquid-vapor interface is approximately equal to the vapor temperature inside the bubble.

Traditionally, an ideal HTC, which often is based on an averaging technique of mole or mass fractions of pure component fluids, is used to represent the heat transfer coefficient in the absence of mass diffusion effects. However, since pool boiling heat transfer can be highly non-ideal, this study also employs Kandlikar's PCS coefficient in place of the mole-weighted ideal HTC for both Stephan Körner and Fugita et al. models, using mixture surface tension correlations Eq. (16) for 2-propanol/water and Eq. (17) for methanol/water mixtures in place of $\sigma_{m}$.

\section{MIXTURE THEORY AND DISCUSSION}

For correlations 2 and 3 listed in Table 1, the ideal superheat $\Delta T_{i d}$, and ideal HTC $h_{l, i d}$ were calculated based on activity coefficients since the mixture fluids in this study are non-ideal. The activity coefficients were determined by equating the molar excess Gibbs energy with the two-parameter Margules equation (McGillis, 1996).

$$
\begin{aligned}
& \ln \gamma_{1}=\left[A_{12}+2\left(A_{21}-A_{12}\right) x_{1}\right] x_{2}^{2} \\
& \ln \gamma_{2}=\left[A_{21}+2\left(A_{12}-A_{21}\right) x_{2}\right] x_{1}^{2}
\end{aligned}
$$

where $\mathrm{A}_{12}$ and $\mathrm{A}_{21}$ are experimentally determined constants (McGillis, 1996). For non-ideal mixtures, the vapor pressure is related to the vapor mole fraction by

Table 1 Binary mixture correlations for pool boiling heat transfer coefficients in binary mixtures.

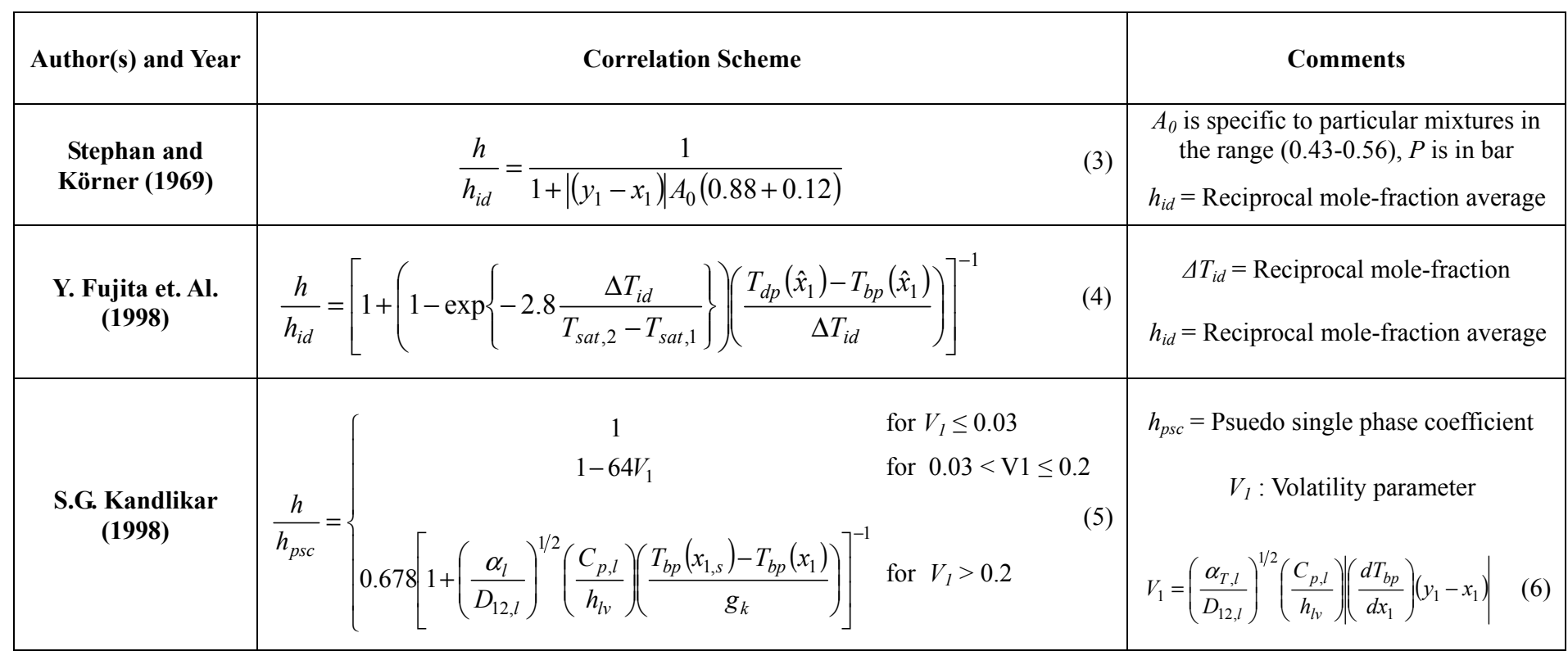




$$
P=\frac{x_{i} \gamma_{i} P_{s a t, i}}{y_{i}}
$$

Using the fact that $\mathrm{y}_{1}+\mathrm{y}_{2}=1$ and $\mathrm{x}_{1}+\mathrm{x}_{2}=1$, the saturation pressure of the mixture can be expressed as:

$$
P=x_{2} \gamma_{2} P_{s a t, 2}+x_{1} \gamma_{1} P_{s a t, 1}
$$

Equating together equations (9) and (10) provides equilibrium concentrations in the liquid and vapor for any system pressure and temperature. Using these calculated liquid and vapor mole fractions, equilibrium phase diagrams are presented by Figs. 1 and 2 for 2propanol/water and methanol/water mixtures respectively.

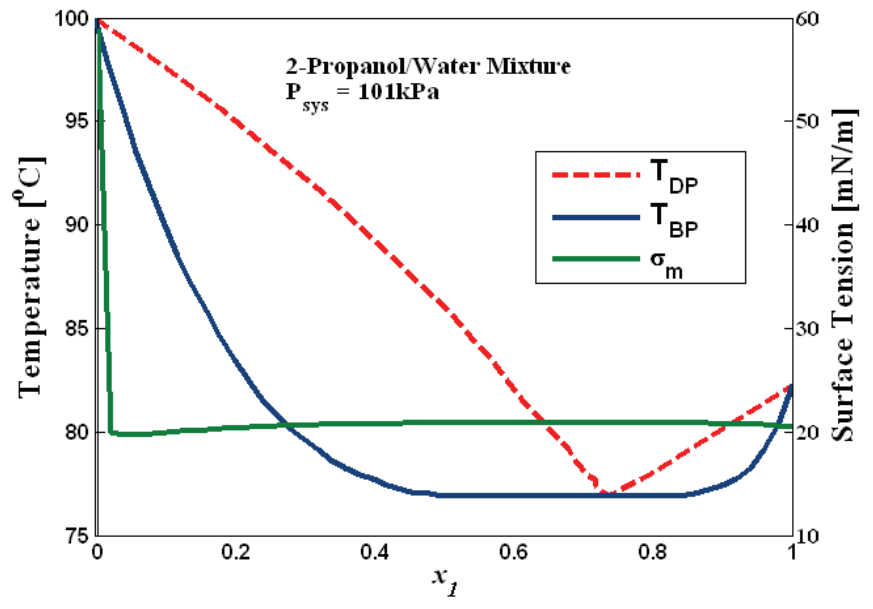

Fig. 1 Liquid-vapor equilibrium phase diagram with mole-fractiondependent surface tension distribution for 2-propanol/water at $101 \mathrm{kPa}$.

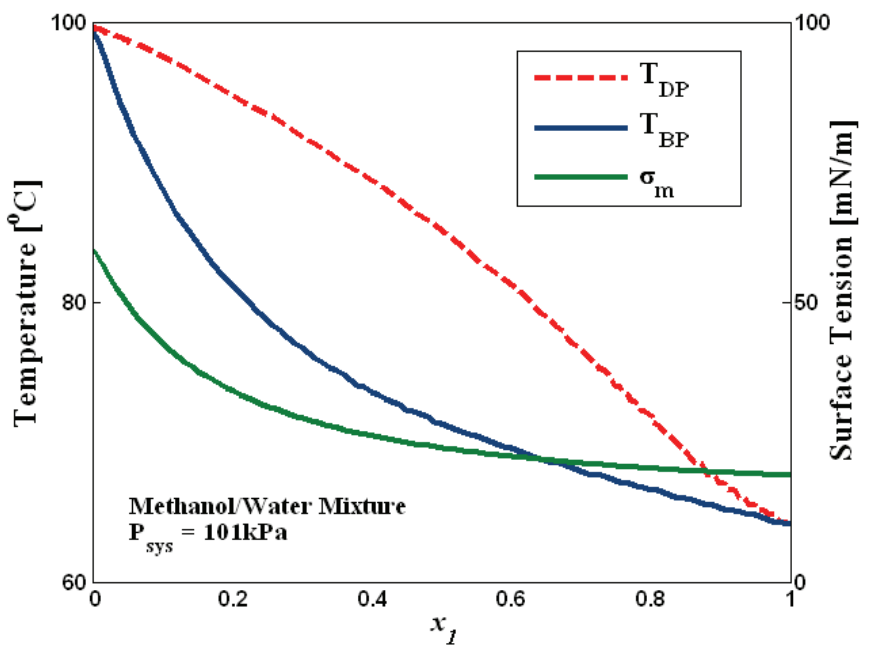

Fig. 2 Liquid-vapor equilibrium phase diagram with mole-fractiondependent surface tension distribution for methanol/water at $101 \mathrm{kPa}$.

To determine the system HTC, an ideal temperature difference was defined by a mole-fraction-weighted average of the superheats for pure component fluids at the same system temperature and pressure, and for a specified heat flux,

$$
\Delta T_{i d}=\Delta T_{1} x_{1}+\Delta T_{2}\left(1-x_{1}\right)
$$

where $\Delta T_{1}$ and $\Delta T_{2}$ are determined from the Stephan-Abdelsalam (1980) mathematical correlation for pure fluids.

$$
\begin{gathered}
\frac{\dot{Q}_{N B}^{\prime \prime} d_{b}}{k_{l}\left(T_{w}-T_{\text {sat }}\right)}=0.23\left(\frac{\dot{Q}_{N B}^{\prime \prime} d_{b}}{k_{l} T_{\text {sat }}}\right)^{0.643}\left(\frac{h_{l v} d_{b}^{2}}{\alpha_{l}^{2}}\right)^{0.371} \\
\times\left(\frac{\rho_{l}-\rho_{v}}{\rho_{l}}\right)^{-1.73}\left(\frac{\alpha_{l}^{2} \rho_{l}}{\sigma_{l} d_{b}}\right)^{0.35}
\end{gathered}
$$

The bubble departure diameter from Eq. (12) is defined by the Borishansky et al. (1981) correlation:

$$
d_{b}\left(\frac{P_{c} M}{k_{B} T_{c}}\right)^{1 / 3}=5.0 \times 10^{5}\left(\frac{P}{P_{c}}\right)^{-0.46}
$$

The ideal HTC is determined by the reciprocal mole fraction-weightedaverage of the pure components, where $x_{l}$ is the mass fraction of the volatile component.

$$
h_{l, i d}=\left[\frac{\hat{x}_{1}}{h_{1}}+\frac{\left(1-\hat{x}_{1}\right)}{h_{2}}\right]^{-1}
$$

The mixture HTC is then determined based on the product of the ideal HTC, $h_{l, i d}$ and a correction factor, $F_{D}$ which accounts for mass diffusion effects.

$$
h_{l}=h_{l, i d} F_{D}
$$

For low concentration conditions of the mixtures considered here, properties such as surface tension, vapor density and saturation temperature may exhibit non-ideal behavior. Through experimentation of various water mixtures containing methanol as well as 1 and 2propanol, Vazquez et al. (1995) presented empirical evidence indicating the non-ideal behavior of surface tension properties for low concentration systems. They further showed that deviation from ideality increases with the length of an organic molecule and decreases with rising system temperature. The non-ideal nature of mixture surface tension properties can be further reflected in the surface tension curves in Figs. 1and 2. In this investigation the mixture surface tension for the 2-propanol/water mixture was evaluated based on Eq. (16) while the methanol/water mixture was evaluated based on Eq. (17), as outlined by McGillis (1996).

$$
\begin{gathered}
\sigma_{m}=\left(\sigma_{2}-\sigma_{1}\right) \exp \left(-30 \sqrt{x_{1}}\right)+\sigma_{1} \\
\sigma_{m}=\left[\psi_{2} \sigma_{2}^{1 / 4}+\psi_{2} \sigma_{1}^{1 / 4}\right]^{4}
\end{gathered}
$$

where $\psi$ is the surface layer superficial volume fraction as outlined by Tamura et al. (1995). Kandlikar (1998) developed an expression that determines the interfacial concentration at the surface of a bubble growing on a heated wall within a binary mixture system:

$$
x_{1, s}=x_{1}-\frac{2.13}{\pi} J a_{o}\left(\frac{\alpha_{l}}{D_{12}}\right)^{1 / 2} \frac{\rho_{v}}{\rho_{l}}\left(y_{1, s}-x_{1}\right)
$$

where $J a_{0}$ is the modified Jakob number that accounts for mass diffusion effects and the rise of the interfacial temperature, 


$$
J a_{o}=\frac{\left(T_{w}-T_{l, s a t}\right)}{\left(\frac{\rho_{v}}{\rho_{l}}\right)\left[\frac{h_{l v}}{C_{p, l}}+\left(\frac{\alpha_{l}}{D_{12}}\right)^{1 / 2} \frac{T_{s a t, s}-T_{s a t}}{g_{k}}\right]}
$$

where

$$
g_{k}=\frac{x_{1}-x_{1, s}}{y_{1, s}-x_{1, s}}
$$

The temperature at the interface of the bubble, $T_{\text {sat,s }}$, was approximated to be equal to the vapor temperature inside it. To determine the interface concentration, an iterative numerical scheme was developed that first solved for the wall superheat for each respective binary mixture correlation, and then determined $x_{1, s}$ by solving simultaneously Eqs. (8) and (9) with Eqs. (18)-20). The calculated interfacial concentrations were then used to find respective thermodynamic properties at the liquid-vapor interface.

The experimental pool boiling data (McGillis, 1996) used in this investigation includes $0.1 \mathrm{M}$ concentrations of 2-propanol and methanol water mixtures in addition to two lower concentrations of $0.015 \mathrm{M} 2$ propanol and $0.04 \mathrm{M}$ methanol water mixtures. The mixture data was obtained from pool boiling experiments on a copper heated surface under a subatmospheric pressure of $7 \mathrm{kPa}$ for the $0.1 \mathrm{M}$ 2-propanol case and a system temperature of $39.8^{\circ} \mathrm{C}$ for all other cases.

\section{RESULTS}

The results indicate that for subatmospheric system conditions with bulk fluid properties, the Kandlikar model correlates adequately for 2propanol/water mixtures, especially for conditions where weak Marangoni effects are present.

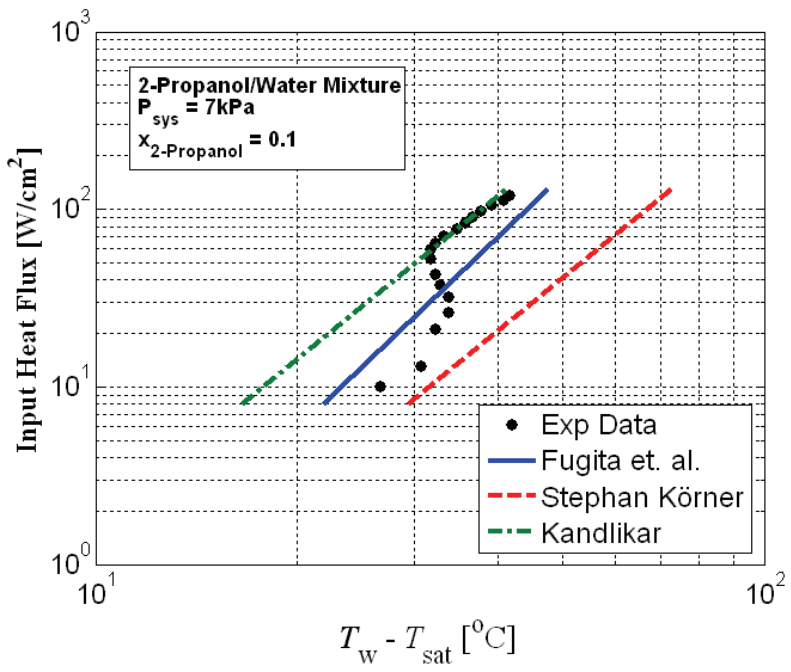

Fig. 3 Comparison between McGillis (1996) experimental data and mixture pool boiling correlations for $0.1 \mathrm{M} 2$-propanol/water at $7 \mathrm{kPa}$ with bulk fluid properties.

In Fig. 3 the Fugita model shows more significant deviations with the larger $0.1 \mathrm{M}$ data, though as the concentration was reduced to $0.015 \mathrm{M}$ the rms error for superheat and heat flux was reduced to $2.7^{\circ} \mathrm{C}$ and $4.9 \mathrm{~W} / \mathrm{cm}^{2}$ respectively. The Stephan Körner model was found to have large deviation for both 2-propanol concentrations. Both models by Fugita and Stephan Körner were originally developed for atmospheric conditions or higher, which can explain the large errors found for both alcohol/water mixtures for the concentrations considered here.

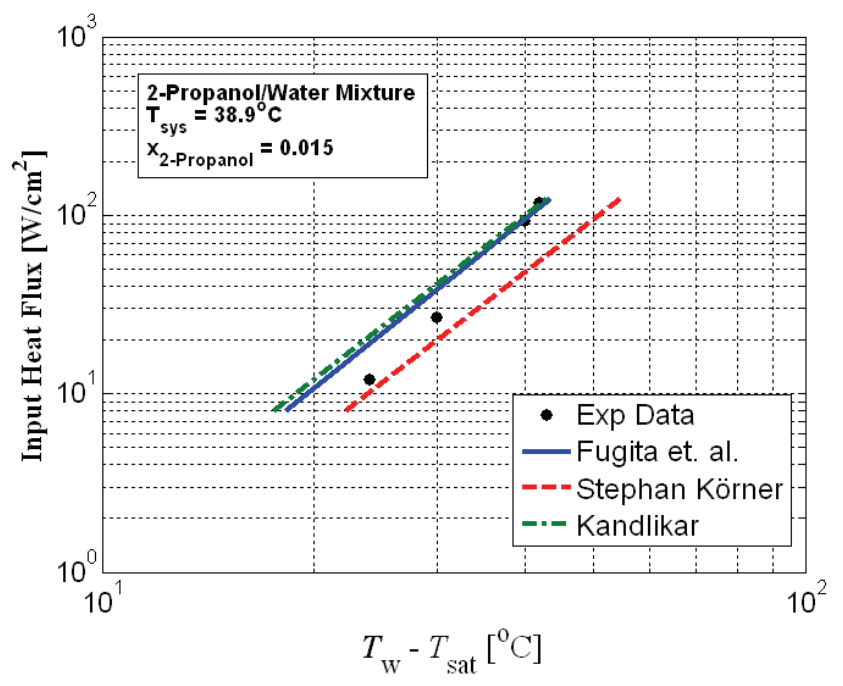

Fig. 4 Comparison between McGillis (1996) experimental data and mixture pool boiling correlations for $0.015 \mathrm{M}$ 2-propanol/water at $38.9^{\circ} \mathrm{C}$ with bulk fluid properties.

From Fig. 4 large deviation was found by all three models for the $0.1 \mathrm{M} \mathrm{methanol/water} \mathrm{mixture,} \mathrm{evaluated} \mathrm{with} \mathrm{bulk} \mathrm{fluid} \mathrm{properties} \mathrm{at}$ subatmospheric conditions. Kandlikar's model had an $8.6^{\circ} \mathrm{C}$ rms error while the Fugita model error decreased with larger superheat values. This deviation further increased as the concentration reduced to $0.04 \mathrm{M}$, with superheat rms values of $12.9^{\circ} \mathrm{C}$ and $5.2^{\circ} \mathrm{C}$ for the models of Kandlikar and Fugita respectively. Similarly the Stephan Körner model also had large deviation with the experimental data for both strong and weak Marangoni concentrations of methanol/water.

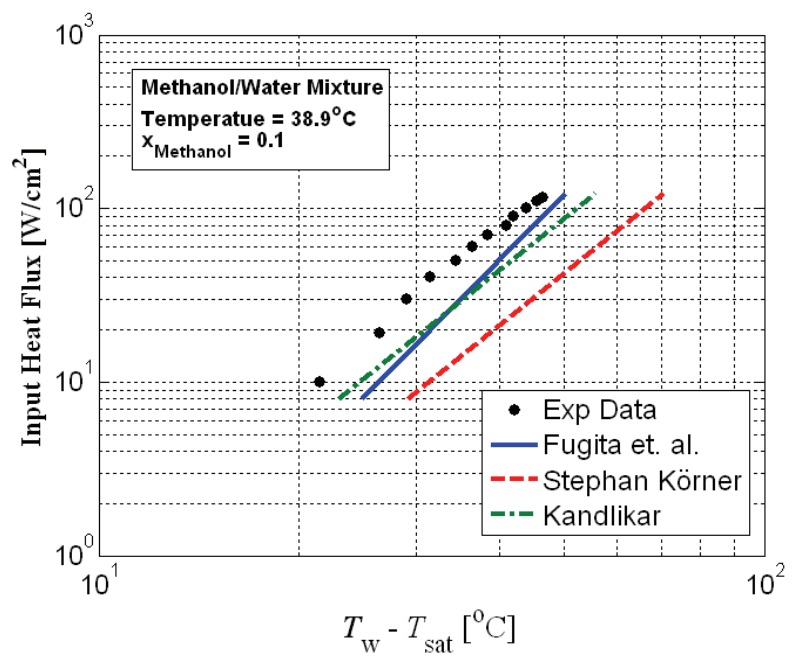

Fig. 5 Comparison between McGillis (1996) experimental data and mixture pool boiling correlations for $0.1 \mathrm{M}$ methanol/water at $38.9^{\circ} \mathrm{C}$ with bulk fluid properties.

This study also explored the modeling impact of using film thermodynamic properties rather than those of the bulk fluid in addition to the use of the PSC coefficient in place of the traditional moleweighted ideal HTC for the Fugita and Stephan Körner models. This particular analysis found a reduction in superheat rms error for the Kandlikar model of $27.0 \%$ and $4.2 \%$ for respective strong and weak concentrations of 2-propanol/water mixtures. Similarly, the Fugita model found an improvement in respective heat flux rms errors of 
$17.6 \%$ and $3.67 \%$ for these respective mixtures. In addition, the strong 2-propanol/water Marangoni concentration accuracy was found to improve for the Stephan Körner model to a superheat rms error of $4.3^{\circ} \mathrm{C}$. These results indicate the use of average properties, using the PSC in place of the ideal HTC, can improve 2-propanol/water mixture predictions for both strong and weak Marangoni concentrations.

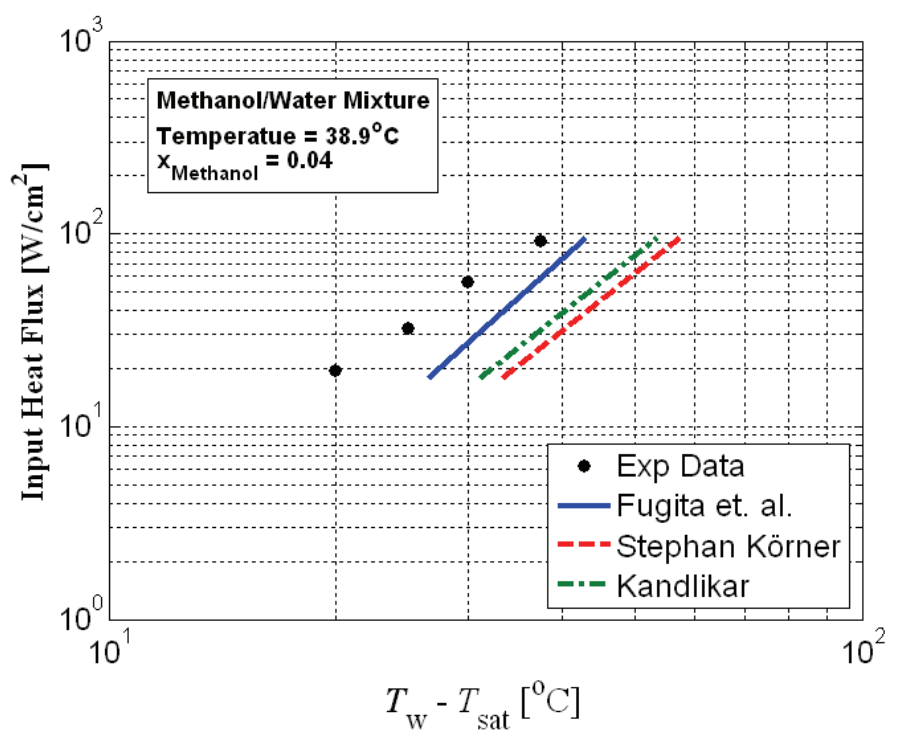

Fig. 6 Comparison between McGillis (1996) experimental data and mixture pool boiling correlations for $0.04 \mathrm{M}$ methanol/water at $38.9^{\circ} \mathrm{C}$ with bulk fluid properties.

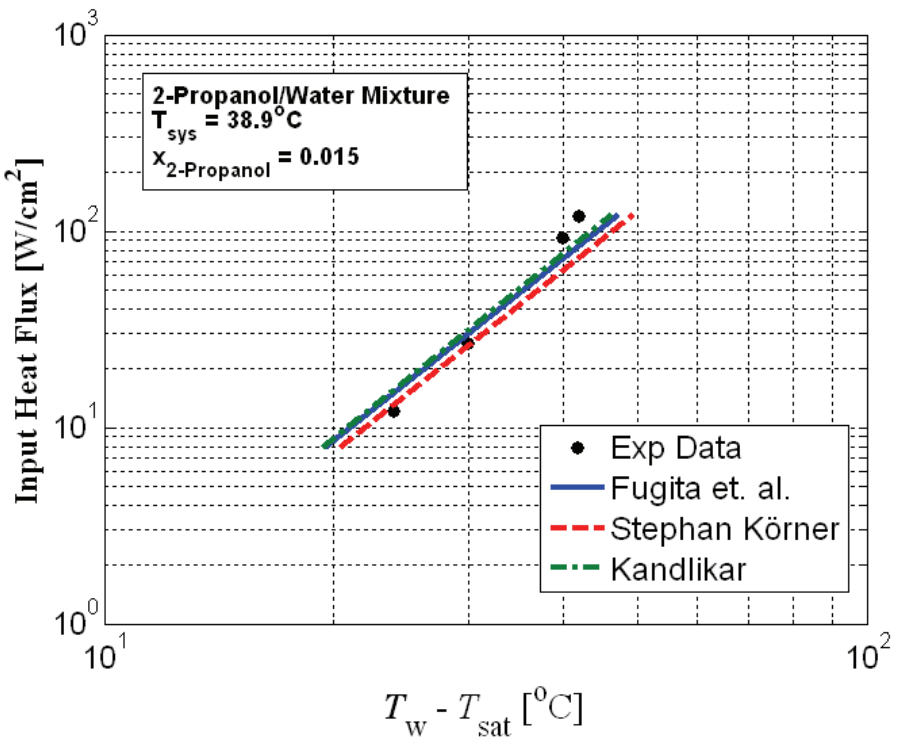

Fig. 7 Comparison between McGillis (1996) experimental data and mixture pool boiling correlations for $0.015 \mathrm{M}$ 2-propanol/water at $38.9^{\circ} \mathrm{C}$ with film fluid properties and PSC coefficient.

This same analysis found a greater impact for the methanol/water mixtures. For the $0.1 \mathrm{M}$ weaker Marangoni concentration, the superheat rms error for the Kandlikar and Fujita models was reduced to $4.9^{\circ} \mathrm{C}$ and $2.4^{\circ} \mathrm{C}$, corresponding to a respective $28.2 \%$ and $54.8 \%$ reduction from the results of the bulk properties using the ideal HTC. For the $0.04 \mathrm{M}$ case, the rms values for Kandlikar, Fugita and Stephan Körner models were reduced to $2.8^{\circ} \mathrm{C}, 3.1^{\circ} \mathrm{C}$ and $2.4^{\circ} \mathrm{C}$, indicating the use of average properties in place of bulk properties as well as the use of the PSC in place of the ideal HTC has a major impact on both strong and weak
Marangoni concentrations of methanol/water mixtures. The results of this study indicates that although Kandlikar's model was able to more accurately predict both strong and weak Marnagoni concentrations, Fugita's model was overall able to predict those for methanol/water best.

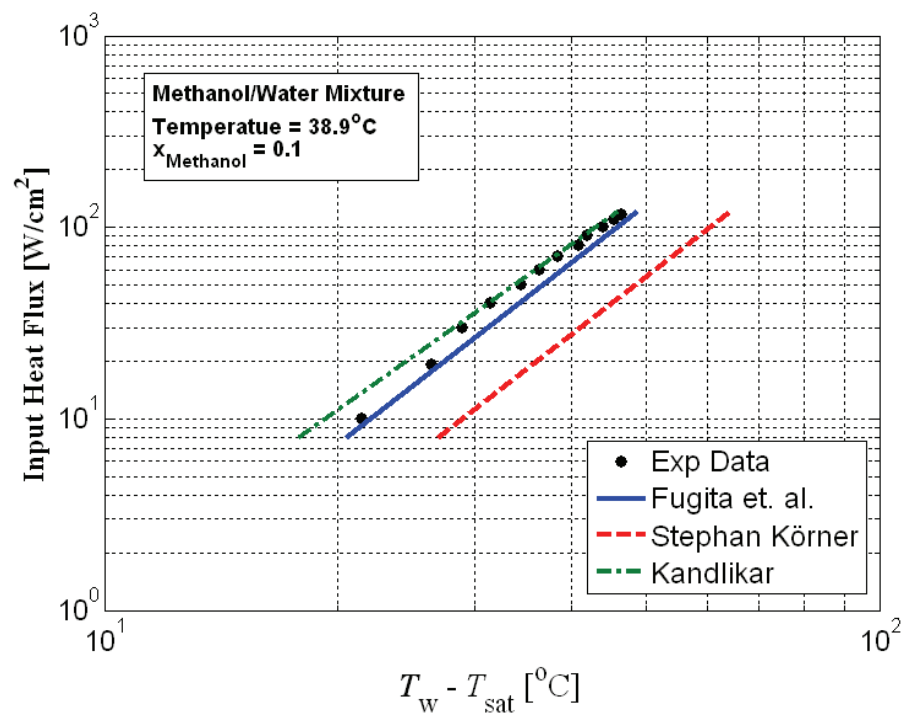

Fig. 8 Comparison between McGillis (1996) experimental data and mixture pool boiling correlations for $0.1 \mathrm{M}$ methanol/water at $38.9^{\circ} \mathrm{C}$ with film fluid properties and PSC coefficient.

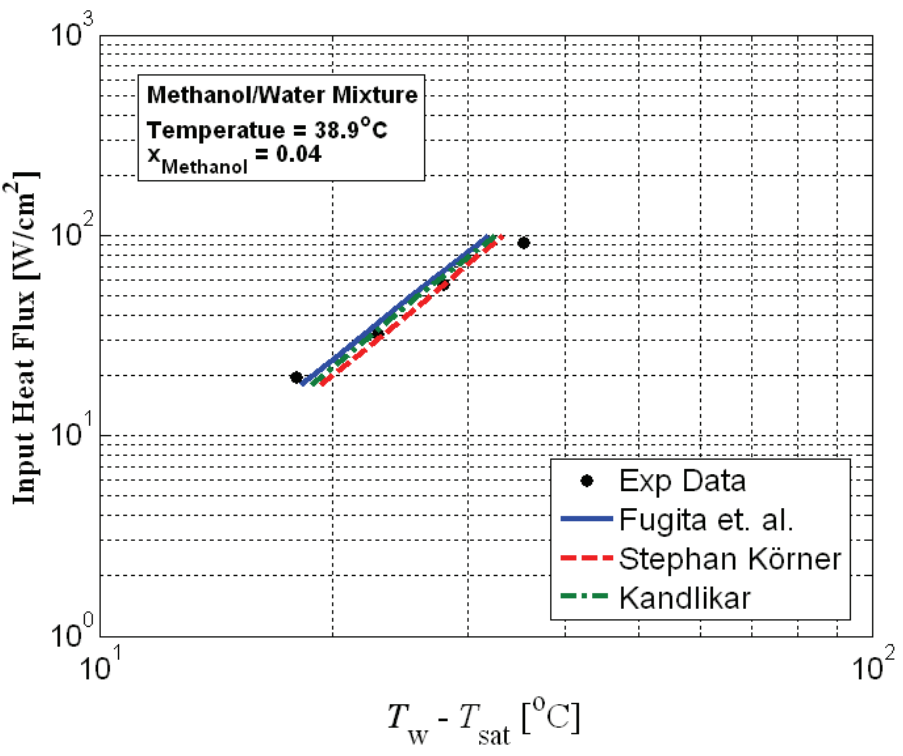

Fig. 9 Comparison between McGillis (1996) experimental data and mixture pool boiling correlations for $0.04 \mathrm{M}$ methanol/water at $38.9^{\circ} \mathrm{C}$ with film fluid properties and PSC coefficient.

\section{CONCLUSIONS}

Binary mixture model comparisons were performed with subatmospheric pressure heat flux and superheat data, for concentrations of 2-propanol/water and methanol/water mixtures that exhibit strong and weak Marangoni phenomena. The results indicate that for bulk fluid properties, the Kandlikar correlation was able to predict well the low pressure 2-propanol/water mixture data for varying concentrations between $0.1 \mathrm{M}$ and $0.015 \mathrm{M}$, better than the models of Fugita and Stephan Körner, with rms superheat deviations of $1.8^{\circ} \mathrm{C}$ and 
$5.8^{\circ} \mathrm{C}$ respectively. However under the same pressure and input heat flux conditions, all three models did not correlate well with the $0.1 \mathrm{M}$ and $0.04 \mathrm{M}$ mixtures of methanol/water, where respective superheat deviations of $5.7^{\circ} \mathrm{C}$ and $6.1^{\circ} \mathrm{C}$ were found for the more predictive Fugita model.

As the concentration of the more volatile fluid decreases, the variation of surface tension at the liquid-vapor interface can be quite large affecting the saturation conditions and heat transfer in the film region. The use of film properties and the PSC coefficient for all models improved the heat flux and superheat predictions for strong Marangoni concentrations. The results suggest a heat flux rms error reduction of up to $59.3 \%$ for $0.015 \mathrm{M} 2$-propanol and $49.1 \%$ for $0.04 \mathrm{M}$ methanol, from their respective bulk fluid properties. The film thermodynamic properties were based on an average approximation of bulk fluid properties and those calculated at the liquid-vapor interface. An idealization was made that the temperature at the liquid-vapor interface was approximately equal to the vapor temperature, for a respective mixture concentration. This method also found greater accuracy predicting superheat values for both strong and weak Marangoni concentrations for 2-propanol/water using Kandlikar's model, with superheat deviations up to $1.8^{\circ} \mathrm{C}$. Fugitas model however was found to better predict both strong and weak concentrations of methanol/water mixtures with superheat deviations up to $1.6^{\circ} \mathrm{C}$.

\section{ACKNOWLEDGEMENTS}

The leading author would like to thank the National Academies of Science Ford Foundation and the NASA Harriett G. Jenkins program for their support through their respective graduate research fellowships. Support for this research by the UC center for information technology research in the interest of society (CITRIS) is also greatly acknowledged.

\section{NOMENCLATURE}

$\begin{array}{ll}C_{p} & \text { specific heat }(\mathrm{J} / \mathrm{kg} \cdot \mathrm{K}) \\ h & \text { enthalpy }(\mathrm{J} / \mathrm{kg}) \\ k & \text { thermal conductivity }(\mathrm{W} / \mathrm{m} \cdot \mathrm{K}) \\ M & \text { molar mass }(\mathrm{kg} / \mathrm{kmol}) \\ \dot{Q}^{\prime \prime} & \text { heat flux }\left(\mathrm{W} / \mathrm{m}^{2}\right) \\ T & \text { temperature }(\mathrm{K}) \\ P & \text { Pressure }(\mathrm{Pa}) \\ x & \text { liquid mass fraction } \\ y & \text { vapor mass fraction } \\ \hat{x} & \text { liquid mole fraction } \\ \hat{y} & \text { vapor mole fraction } \\ D & \text { Diffusion Coefficient }\left(\mathrm{m}^{2} / \mathrm{s}\right) \\ d & \text { bubble departure diameter }(\mathrm{m}) \\ G r e e k ~ S y m b o l s \\ \alpha & \text { thermal diffusivity }\left(\mathrm{m}^{2} / \mathrm{s}\right) \\ \rho & \text { density }\left(\mathrm{kg} / \mathrm{m}^{3}\right) \\ \sigma & \text { surface tension }(\mathrm{N} / \mathrm{m}) \\ \gamma & \text { activity coefficient }\end{array}$

$\begin{array}{ll}\text { Subscripts } & \\ 1 & \text { mixture component fluid 1 } \\ 2 & \text { mixture component fluid 2 } \\ N B & \text { nucleate boiling } \\ \text { sat } & \text { saturation condition } \\ \text { id } & \text { ideal } \\ b & \text { bubble } \\ c & \text { critical } \\ s & \text { interface } \\ v & \text { vapor }\end{array}$

$\begin{array}{ll}l & \text { liquid } \\ b p & \text { bubble point } \\ d p & \text { dew point }\end{array}$

\section{REFERENCES}

Armijo, K.M., and Carey, V.P., 2010, “An Experimental Study of Heat Pipe Performance Using Binary Mixture Fluids that Exhibit Strong Concentration Marangoni Effects", Paper No. 23255, Proceedings of $14^{\text {th }}$ ASME IHTC Conference, Washington, D.C.

McGillis, W.R. and V.P. Carey, 1996, "On the Role of Marangoni Effects on the Critical Heat Flux for Pool Boiling of Binary Mixtures", J. Heat Transfer, 118, 103-109.

doi:10.1115/1.2824021

Stephan, K. and Abdelsalam, M., 1980, "Heat-Transfer Correlations for Natural Convection Boiling", Int. J. Heat and Mass Transfer, 23, 7387.

doi:10.1016/0017-9310(80)90140-4

McGillis, W.R., 1993, "Boiling from Localized Heat Sources in Pure and Binary Fluid Systems", Ph.D. Thesis, U.C. Berkeley, Berkeley, CA.

Stephan, K., and Körner, M., 1969, "Berechnung des Wärmeübergangs Verdamp Fender Binärer Flüssigkeitsgemische", Chemi Ing. Tech., 41, 409-417.

\section{doi:10.1002/cite.330410702}

Fujita, Y., Bai, Q., and Tsutsui, M., 1996, "Heat Transfer of Binary Mixtures in Nucleate Pool Boiling", Proceedings of 2nd Eur. Thermal Sci. and 14th UIT Nat. Heat Trans. Conf., 1639-1646.

Fujita, Y., and Tsutsui, M., 1997, "Heat Transfer in Nucleate Boiling of Binary Mixtures”, JSME Int. J., 40, 134-141.

Kandlikar, S.G., 1998, "Boiling Heat Transfer with Binary Mixtures: Part I - A Theoretical Model for Pool Boiling", ASME J. Heat Transfer, 120, 380-387.

$\underline{\text { doi: } 10.1115 / 1.2824260}$

Jungnickel, H., Wassilew, P., and Kraus, W.E., 1982, "Investigations on the Heat Transfer of Boiling Binary Refrigerant Mixtures", Int. J. Refrigeration, 3, 129-133. doi:10.1016/0140-7007(80)90092-4

Calus, W.F., and Leonidopoulus, D.J., 1974, "Pool Boiling - Binary Liquid Mixtures", Int. J. Heat and Mass Transfer, 17, 249-256. doi:10.1016/0017-9310(74)90086-6

Vázquez, G., Alvarez, E., and Navaza, J.M., 1995, "Surface Tension of Alcohol + Water from 20 to $50^{\circ}$ C", J. Chem. Eng. Data, 40, 611-614. doi:10.1021/je00019a016

Carey, V.P., 2008, Liquid-Vapor Phase-Change Phenomena, $2^{\text {nd }}$ ed., Taylor \& Francis Group, New York, NY.

Borishansky, V.M., Danilova, G.N., Gotovsky, M.A., Borishansky, A.V., Danilova, G.P., and Kupryanova, A.V., 1981, "Correlation of Data on Heat Transfer in, and Elementary Characteristics of the Nucleate Boiling Mechanism", Heat Transfer-Soviet Research, 13, 100-116.

Tamura, M., Kurata, M., Odani, H., 1955, "Practical Method for Estimating Surface Tensions of Solutions”, Bull. Chem. Soc. Japan, 28, 83-88. 